\section{Aquatic Toxicology}

Volume 83, Issue 4, 1 August 2007, Pages 254-262

http://dx.doi.org/10.1016/j.aquatox.2007.04.009

(c) 2007 Elsevier B.V. All rights reserved
Archimer, archive institutionnelle de l'Ifremer http://www.ifremer.fr/docelec/

\title{
Toxicity assessment of peptaibols and contaminated sediments on Crassostrea gigas embryos
}

\author{
Laurence POIRIER ${ }^{1^{*}}$, Françoise QUINIOU ${ }^{2}$, Nicolas RUIZ ${ }^{1}$, Monique MONTAGU ${ }^{1}$, \\ Jean-Claude AMIARD ${ }^{1}$, Yves François POUCHUS ${ }^{1}$ \\ ${ }^{1}$ Université de Nantes, Nantes Atlantique Universités, SMAB, EA2160, Faculté de pharmacie, 1 rue Gaston Veil - \\ BP 53508, Nantes, F-44000 France \\ ${ }^{2}$ IFREMER- BE/EX, Centre de Brest - BP 70, 29280 Plouzané, France \\ * Corresponding author. Tel.: +33 2511257 52; Fax: +33 2511256 79; E-mail address: \\ laurence.poirier@univ-nantes.fr
}

\begin{abstract}
:
Peptaibols are known membrane-modifying peptides that were recently detected in marine sediments and mussels collected from a shellfish farming area (Fier d'Ars, Atlantic coast, France). In this investigation, embryotoxicity bioassays with oysters (Crassostrea gigas) were performed to assess acute toxicity of alamethicin and different groups of peptaibols produced by a Trichoderma longibrachiatum strain isolated from marine environment. C. gigas embryos appeared very sensitive to all the metabolites examined with higher toxic effects for long-sequence peptides $\left(\mathrm{EC}_{50}\right.$ ranging from 10 to $64 \mathrm{nM}$ ). D-shaped larvae with mantle abnormality were particularly noticed when peptaibol concentrations increased. Disturbances of embryogenesis were also observed following exposure to organic and aqueous extract of sediments from Fier d'Ars $\left(E C_{50}=42.4\right.$ and $6.6 \mathrm{~g} \mathrm{~L}^{-1}$ dry weight, respectively). Although peptaibol concentrations measured in these sediments could explain only a part of the toxic effects observed, this study suggests that these mycotoxins can induce larval abnormalities in a population of exposed animals at environmentally realistic concentrations. Their detection in coastal areas devoted to bivalve culture should be taken into account.
\end{abstract}

Keywords: Marine fungi; Mycotoxins; Bivalve bioassay; Embryotoxicity; Risk assessment 
Introduction

The peptaibols are small linear peptides produced by widely distributed filamentous

\section{.} fungi including terrestrial and marine species (Degenkolb et al., 2003). They constitute the main subgroup (approximately 86\%) of the constantly growing family of peptaibiotics including more than 450 reported compounds (Whitmore and Wallace, 2004b). Most of the peptaibiotics $(\approx 80 \%$ ) have been isolated from fungal strains belonging to the genus $\underline{\text { Trichoderma }}$ or its teleomorph $\underline{\text { Hypocrea. }}$. They range between 500 and 2200 Da and show a high content of $\alpha$ aminoisobutyric acid which represents the main common characteristic of these diversified molecules (Chugh and Wallace, 2001). Peptaibols possess an acylated Nterminus and a C-terminal residue that consists of a free 2-amino alcohol (Degenkolb et al., 2003; Degenkolb et al., 2006).

Peptaibols and other peptaibiotics present unique physico-chemical and biological activities depending on particular structural properties. Their helical structures allow them to interact with natural and artificial bilayers to form pores or voltage-dependent ion channels increasing membrane permeability (Rebuffat et al., 1999; Peltola et al., 2004; Whitmore and Wallace, 2004a). Related to this particular ability, a variety of biological activities such as antibacterial, antifungal, and occasionally antiviral, insecticidal and antiparasitic activities have been described. Bioactivity of peptaibiotics includes also uncoupling of oxidative phosphorylation in mitochondria, stimulation of catecholamine secretion from adrenal cells, activation of membrane-bound enzymes such as adenylate and guanylate cyclases, cytotoxicity, neurotoxicity and neuroleptic effects (for reviews, see Szekeres et al., 2005 and Krause et al., 2006). The increasing exploitation of peptaibol-producing strains as biological 
1

control agents against phytopathogens illustrates the great interest of these peptides (Degenkolb et al., 2006; Xiao-Yan et al., 2006).

(6)

In a marine area devoted to bivalve culture (Fier d'Ars, Atlantic coast, France), the presence of peptaibols and peptaibols-producing $\underline{\text { Trichoderma }}$ sp. strains has recently been detected in sediments which showed a high toxicity for mussel larvae (Mytilus edulis) in the absence of significant contaminations (metals, PCBs, HAPs, pesticides, antibiotics) or eutrophication (Amiard-Triquet et al., 2003; Poirier et al., 2007b). The ability of Trichoderma sp. to grow in hypersaline environment and to produce such metabolites has been already demonstrated in laboratory marine-like culture conditions (Landreau et al., 2002; MohamedBenkada et al., 2006). Identification of peptaibols in marine natural samples can be considered as a proof of the development of these saprophytic fungi in marine sediments. Presence of these peptides was also reported in marine bivalves (Poirier et al., 2007b) and they were shown to be accumulated by filter-feeder molluscs in experimental contamination inducing physiological stress (Sallenave-Namont et al., 1999). The existence of such compounds in shellfish farming areas could represent a risk for shellfish populations and poisoning risks through the consumption of contaminated shellfish.

The present study was designed to establish a causal relationship between peptaibol concentrations measured in sediments and potential toxic effects for bivalve organisms. Different bioassays using various marine organisms have been proposed to assess the toxicity of pollutants and the biological quality of waters and sediments in coastal areas. The embryotoxicity test with the oyster Crassostrea gigas is recognized as one of the most sensitive of all classically used (His et al., 1999). Eggs, embryos and larvae are less tolerant to toxic compounds than adults and therefore represent the critical life stages for toxicological 
88

89

90

91

92

93

94

studies (Connor, 1972; Martin et al., 1981). Acute toxicity bioassays using embryo-larval development of $\underline{C \text {. gigas }}$ were performed on alamethicin and different groups of peptaibols produced by a strain of Trichoderma longibrachiatum isolated from marine environment. To know the potential effects caused by environmental levels, the embryotoxicity of purified extract of Fier d'Ars sediment and its elutriate was also studied.

3

(1)

\section{Bioassay procedure}

\section{Materials and methods}

The bioassay followed the method reported by His et al. (1997) and Quiniou et al. (2005). Mature adults of $\underline{C \text {. gigas }}$ were induced to spawn by thermal stimulation (alternating immersion in seawater of $15^{\circ} \mathrm{C}$ and $28^{\circ} \mathrm{C}$ for 30 min each time). Spawing males and females were individually isolated in beakers with $0.2 \mu \mathrm{m}$ natural filtered seawater. The oocytes and sperm of different oysters were observed under an inverted microscope, and the best reproductive pair (regular oocytes and very mobile spermatozoa) was selected for the experiment. Oocytes and sperm solutions were respectively sieved trough a $100 \mu \mathrm{m}$ and a 32 $\mu \mathrm{m}$ mesh to remove debris. The oocytes were fertilized using a few milliliters of the spermdense solution. Fifteen minutes after fertilization, the embryos were counted and placed in 30 $\mathrm{mL}$ transparent polypropylene vessels filled with the different media to be tested (1000 eggs; three replicates per treatment). The embryos were incubated at $24{ }^{\circ} \mathrm{C}$ for $22 \mathrm{~h}$ until D-larvae stages were obtained. Cupric sulphate $\left(\mathrm{CuSO}_{4}, 5 \mathrm{H}_{2} \mathrm{O}\right)$ was used as a reference toxicant and

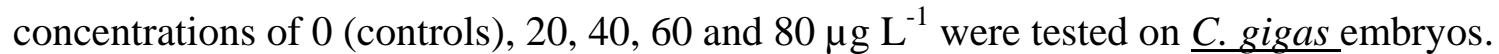


After incubation, $0.5 \mathrm{~mL}$ of $8 \%$ buffered formalin was added to each vessel, and abnormalities were determined by direct observation of 100 individuals (chosen at random

113 from the 1000 in each vessel). According to His et al. (1997), the categories of abnormal

114 larvae included: segmented eggs, normal or malformed embryos that had not reached the D-

115 larval stage; and D-larvae with shell abnormalities (convex hinge, indented shell margins, 116 incomplete shell) or protruded mantle.

\section{Peptaibol treatments}

\subsection{General}

Embryotoxicity tests were conducted with different group of peptaibols, alamethicin and microheterogeneous mixtures of peptaibols isolated from a marine strain of $\underline{T}$.

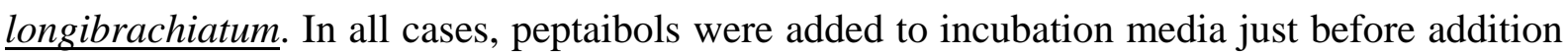
of the embryos $(\approx 1 \mathrm{~min})$. Peptaibol ethanolic solution $(20 \mu \mathrm{L})$ was added in $30 \mathrm{~mL}$ filtered seawater. Concentrations of ethanolic solutions were prepared in order to test the final following concentrations: 0 (ethanol for control), 1, 10, 50, 100, and $500 \mu \mathrm{g} \mathrm{L}^{-1}$. For each nominal concentration tested, $0.5 \mathrm{~mL}$ of incubation medium was sampled at the beginning $(\mathrm{t}=$ $0)$ and the end $(t=22 h)$ of the experiment to determine peptaibol concentrations by high performance liquid chromatography (HPLC) / mass spectrometry (MS) according to the method described by Poirier et al. (2007a). Aqueous aliquot was washed with

130 dichloromethane/methanol mixture with the following proportion:

131 dichloromethane/methanol/aqueous aliquot 2:2:1 (v/v). The aqueous phase containing salts 132 was washed two other times with dichloromethane. The totality of organic phases were then combined and evaporated to dryness before HPLC/MS analysis. 


\subsection{Alamethicin}

Alamethicins are 20-residue peptaibols isolated from a strain of Trichoderma viride (Sigma Aldrich, Ref. A4665). The mixture used consisted of analogues F50/5, F50/6a, F50/7 and F50/8b (Kirschbaum et al., 2003; Poirier et al., 2007a).

\subsection{Peptaibol isolated from a T. longibrachiatum marine-related strain}

\section{Fungal strain and cultures}

The strain used for peptaibol production was a Trichoderma longibrachiatum Rifai isolated from mussels ( $\underline{\text { Mytilus edulis }}$ ) collected in a marine area devoted to bivalve culture from the estuary of the Loire river (Tharon, France $-47^{\circ} 10^{\prime} \mathrm{N} 2^{\circ} 10^{\prime} \mathrm{W}$ ). The original isolate was deposited in the SMAB Marine Fungal collection of University of Nantes as MMS 151 reference. The identification of this strain was based on molecular methods and reported by Mohamed-Benkada et al. (2006). Fungal cultures were performed on Dextrose Casein Agar medium prepared with seawater (dextrose $40 \mathrm{~g} \mathrm{~L}^{-1}$; enzymatic digest of casein $10 \mathrm{~g} \mathrm{~L}^{-1}$; agar $15 \mathrm{~g} \mathrm{~L}^{-1}$ ) in $20 \mathrm{~cm}$ Petri dishes (125 mL of medium/dish). Cultures were incubated for 10 days at $27^{\circ} \mathrm{C}$.

\section{Extraction and purification of peptaibols}

Fungal biomass (mycelium and conidia) was scraped from the agar surface and steeped three times in dichloromethane/methanol mixture $(1: 2,2: 1$ then $1: 1, \mathrm{v} / \mathrm{v})$ for $2 \mathrm{~h}$ at room temperature. The combined organic phases were filtered under vacuum $(0.45 \mu \mathrm{m}$ PTFE membrane filters, Sartorius, Göttingen, Germany), washed with water and evaporated to dryness. Chromatography on an open silica gel column (30 x 300 mm, $60 \AA \AA$ 35-75 $\mu \mathrm{m}$, SDS, Peypin, France) was performed on the crude extract obtained with dichloromethane, acetone and methanol as eluants. Two groups of peptaibols (A and B) were eluted in the acetonic and 
160

161

162

163

164

165

166

167

168

169

170

171

172

173

174

175

176

177

178

179

180

181

182

183

methanolic phases, respectively. A second chromatographic separation on a silica gel column (20 mm x $300 \mathrm{~mm}$ ) was then performed on each group. Elution was realized with various dichloromethane/methanol mixtures (90:10, 88:12, 85:15, 80:20, v/v). As final step, a preparative HPLC-UV on a modular apparatus including a ConstaMetric III pump (LDC S.A., Paris, France), a SpectroMonitor ${ }^{\circledR}$ D (LDC) and a 4.6 x $250 \mathrm{~mm}$ Inertsil ODS-3 column (Interchim, Montluçon, France) was carried out only on group B fractions to achieve their purification. The mobile phase consisted of a methanol/ $\mathrm{H}_{2} \mathrm{O}(85: 15, \mathrm{v} / \mathrm{v})$ mixture delivered at a constant flow rate of $5 \mathrm{~mL} / \mathrm{min}$. Detection was performed at $230 \mathrm{~nm}$.

\section{Mass spectrometry analysis}

The purified fractions of both groups were analyzed on a modular HPLC system consisting of a Spectraphysics Spectra System P2000 pump, an AS 100XR autosampler (Thermo Separation Products, San Jose, CA, USA) equipped with a Kromasil C-18 5- $\mu$ m reverse-phase $2.0 \times 250 \mathrm{~mm}$ column (Interchim) heated to $40^{\circ} \mathrm{C}$ and coupled to a Finnigan Matt LCQ iontrap mass spectrometer with an electrospray interface (Thermo Separation Products). The mobile phase consisted of a methanol/ $\mathrm{H}_{2} \mathrm{O}(85: 15, \mathrm{v} / \mathrm{v})$ mixture delivered at a constant flow rate of $0.2 \mathrm{~mL} / \mathrm{min}$. Sample injection volume was $5 \mu \mathrm{L}$. All mass analyses were performed in the positive mode. The mass spectrometer parameters were previously adjusted to ensure optimal detection of peptaibols (Poirier et al., 2007a). The spray voltage was set to $4.50 \mathrm{kV}$, the capillary temperature to $266^{\circ} \mathrm{C}$ and the capillary voltage to $42 \mathrm{~V}$. The nitrogen flow rates were respectively 89 and 37 (arbitrary units) for sheath and auxiliary gas. Parameters of ion optic transmission were adjusted to $55 \mathrm{~V}$ for Tube Lens Offset, $-3.50 \mathrm{~V}$ for Multipole 1 Offset, -6 V for Multipole 2 Offset and $400 \mathrm{~V}$ for Multipole RF Amplifier (peak to peak). $\mathrm{MS}^{\mathrm{n}}$ analyses were carried out with a collision energy of 32\% and an isolation width of $1 \mathrm{u}$. 
184 All spectra acquisitions and reworks were done using LCQ Xcalibur 1.3 software (Thermo 185 Separation Products). The purest fractions were chosen for bioassays.

186

187

188

189

190

191

192

193

194

195

196

197

198

199

200

201

202

203

204

205

206

\section{Sediment treatments}

Sediments from Fier d'Ars (Ré Island - 46 $13^{\prime} \mathrm{N} 1^{\circ} 29^{\prime} \mathrm{W}$ ) were collected in March 2006. All samples were transported from the site to the laboratory in isothermic containers and frozen at $-20^{\circ} \mathrm{C}$ until bioassays. The bioassay was conducted with organic extract of sediment and elutriate.

A purified organic extract was prepared according to the method reported in Poirier et al. (2007a). Briefly, the steps were as follows: extraction of $10 \mathrm{~g}$ of sediment wet weight (ww) with $3 \times 25 \mathrm{~mL}$ of acetone / acetic acid 1\% (v/v); sonication of the sediment-solvent mixture for $15 \mathrm{~min}$; centrifugation at $700 \mathrm{~g}$ for $5 \mathrm{~min}$; filtration; evaporation to dryness; purification of crude extracts by vacuum liquid chromatography on a diol-silica gel column (Supelco, Bellefonte, PA, USA); elution performed with successive dichloromethane/ethanol mixtures (100:0, 98:2, 90:10 and 50:50, v/v). The concentrations of peptaibols were determined in each fraction by HPLC/MS analysis and previously reported by Poirier et al. (2007a). Fractions at 10 and $50 \%$ of ethanol, eluting peptaibols, were combined, evaporated and frozen at $-20^{\circ} \mathrm{C}$ prior to the bioassay.

As reported for peptaibol treatments (see section 2.1. of Materials and methods), this organic extract was taken up by ethanol and added to incubation media just before the embryos by addition of ethanolic solution $(20 \mu \mathrm{L})$ in vessels filled with $30 \mathrm{~mL}$ filtered seawater. Concentrations of ethanolic solutions were prepared in order to test the final 
208 following concentrations equivalent to 0 (ethanol for control), 0.4, 2, and $4 \mathrm{~g} \mathrm{~L}^{-1}$ of sediment 209 dry weight (dw).

210

211 Elutriate was prepared using a modified Melzian method (1990) according to Geffard et 212 al. (2004). Frozen sediments were shaken mechanically at $500 \mathrm{rpm}$ in glass bottles with 213 filtered seawater at a ratio of 1:4 (sediment/water, v/v) for $8 \mathrm{~h}$ and allowed to decant for a 214 further $8 \mathrm{~h}$ period before removal of the supernatant. For toxicity test, an aliquot was diluted 215 with filtered seawater to the concentrations equivalent to 0 (control), $0.15,1,7,14,71$ and $143 \mathrm{~g} \mathrm{~L}^{-1}$ of sediment dw.

\section{Toxicological data analysis}

Mean percentage of abnormalities and standard deviation were calculated for each treatments and corrected for effects in control tests by applying Abbot's formula (Emmens, 1948). If abnormalities in the controls (seawater and ethanol) were $20 \%$ or more, the test was judged invalid and repeated.

Bartlett's test was used to examine homogeneity of variance. If the data failed this test, $\arcsin \sqrt{ } \mathrm{p}$ transformations were applied to achieve homogeneity. The null hypothesis (peptaibol and sediment treatments had no effects on embryogenesis) was tested by comparison of percentages of abnormal larvae at each concentration to the controls using a one-level ANOVA. Whenever the null hypothesis was rejected ( $\alpha=0.05$ ), non-linear regressions were performed in order to assess $\mathrm{EC}_{50} \pm \mathrm{SD}$ by using Macro REGTOX program 230 (version 7.0.5), according to Vindimian et al. (1983). 
233 of variation (CV) calculated for the peptaibol and copper treatments. Covariance analysis was 234 used to test the difference between the two regression lines established between the two 235 sedimentary treatments.

236

\section{Results}

\section{Validity of bioassays}

240

In the experiments carried out, the seawater controls showed $84 \pm 4 \%$ of normally

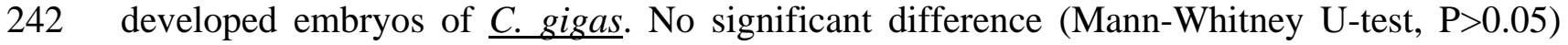

243 was found in development to D-larvae in the ethanol controls (82 $\pm 0.2 \%)$.

Experimentations performed with copper as reference toxicant confirmed the good repeatability of each assay but highlighted differences of embryo sensitivity. For the assay realized to estimate sediment toxicity, a mean $\mathrm{EC}_{50} \pm \mathrm{SD}$ of $40 \pm 0.4 \mu \mathrm{g}$ of $\mathrm{CuSO}_{4} \mathrm{~L}^{-1}$ was obtained $(\mathrm{CV}=1 \%, \mathrm{n}=3)$, whereas a mean of $22 \pm 1 \mu \mathrm{g}$ of $\mathrm{CuSO}_{4} \mathrm{~L}^{-1}(\mathrm{CV}=5 \%, \mathrm{n}=3)$ was calculated for the assay carried out to determine peptaibol toxicity. These values were both within the $\mathrm{EC}_{50}$ acceptability range (21-45 $\mu \mathrm{g} \mathrm{L}^{-1}$ ) (Quiniou et al., 2005).

\section{Peptaibol treatments} Two main peptaibol fractions were obtained from the culture of $\underline{T}$. longibrachiatum and 
256 When analyzed by HPLC/MS, the two-peptide groups appeared as complex mixtures of 257 peptaibol analogues. MS/MS analysis allows identification of the main peptaibols by 258 sequence comparison with literature data.

259 The first group (Fig. 1A) had $[\mathrm{M}+\mathrm{Na}]^{+}$ions at $\mathrm{m} / \mathrm{z} 1169.9,1183.9,1197.9$ and 1211.9, 260 suggesting a mixture of 11-residue peptides similar to trichobrachins A, trichorovins TV, 261 trichorozins, hypomurocins A or harzianins HB and HK (Iida et al., 1995; Wada et al., 1995;

262 Rebuffat et al., 1996; Augeven-Bour et al., 1997; Becker et al., 1997; Mohamed-Benkada et 263 al., 2006).

264 In the second group (Fig. 1B-D), doubly charged $[\mathrm{M}+2 \mathrm{Na}]^{2+}$ ions at $\mathrm{m} / \mathrm{z}$ 991.2, 991.7, 265998.3 and 1002.6 were observed, indicating a mixture of long-sequence peptides with 20 266 residues, close to longibrachins and trichokonins (Huang et al., 1995; Huang et al., 1996; 267 Leclerc et al., 1998; Leclerc et al., 2001; Landreau et al., 2002).

\subsection{Observation of abnormalities}

Among the different abnormalities observed, abnormal D-shaped larvae presenting a protruding mantle associated to an irregular shell were frequently recorded with peptaibol treatments (Fig. 2). Compared to the controls for which mantle abnormalities represent $28 \pm$ $4 \%$ of observed deformities, the percentage of larvae developing this category of abnormality

274 significantly increased according to a linear relation with the percentage net response obtained 275 following exposures to the different groups of peptaibols and consequently with the peptaibol 276 concentrations in incubation media $(r=0.74, n=57)$. It reached $66 \pm 13 \%$ when the 277 percentage of abnormalities was over $90 \%$. 


\subsection{Embryotoxicity of peptaibols}

The results of peptaibols quantification in tested media showed an important and variable

decrease of solubilized compounds during the experiment. Expressed as a percentage of loss after $22 \mathrm{~h}(\mathrm{y})$, this decrease was significantly correlated to the initial peptaibols concentration

(x) by the following non linear regression $(r=0.85, n=10)$ :

$$
y=-14.67 \operatorname{Ln}(x)+108.79
$$

Thus, the concentrations of peptaibols in incubation media were expressed in effective concentrations measured at the beginning of the experiment.

The effects of each group of peptaibols were significant on $\underline{C \text {. gigas embryogenesis }}$ $(\mathrm{P}<0.0001)$. In general, an important variability between responses of replicates was observed. The mean coefficient of variation (35 $\pm 19 \%)$ was significantly superior to the mean

CV obtained for copper test $(6 \pm 7 \%)$ (Mann-Whitney U-test, $\mathrm{P}<0.01)$ indicating that this lack of repeatability was certainly related to the variation of compound solubility in incubation media.

Alamethicin showed $22 \pm 4 \%$ of abnormalities at the lowest concentration tested ( $0.5 \mathrm{nM}$;

Fig. 3). Its toxicity increased strongly to gain $64 \pm 38 \%$ at $23 \mathrm{nM}$. No significant increase of abnormalities was observed at higher concentrations. The calculated $\mathrm{EC}_{50}$ was $31 \pm 3 \mathrm{nM}$.

Toxic effects of the long-chain peptaibols isolated from $\underline{T}$. longibrachiatum were not 298 significantly different from the controls at low concentrations (up to $1.2 \mathrm{nM}$ ) (Fig. 3). 299 Percentage of abnormalities increased significantly to reach a maximum of $95 \pm 5 \%$ at $61 \mathrm{nM}$. The $\mathrm{EC}_{50}$ was estimated to be $10 \pm 3 \mathrm{nM}$. 
$303(0.4 \mathrm{nM})$. Above $4 \mathrm{nM}$, toxicity reaches a maximum and seems to be independent of the

304 peptide concentration. An $\mathrm{EC}_{50}$ of $64 \pm 8 \mathrm{nM}$ was extrapolated.

305

\section{Embryotoxicity induced by sediment extracts}

307

308

309

310

311 4

Purified extract of sediments from Fier d'Ars had significant effects on $\underline{C \text {. gigas }}$ embryogenesis $(\mathrm{P}<0.002)$. No differences were observed between the controls and the lowest concentration tested $\left(0.4 \mathrm{~g} \mathrm{~L} \mathrm{~L}^{-1} \mathrm{dw}\right)$. Abnormalities increased slowly at the higher concentrations and reached $20.5 \pm 5.5 \%$ at the highest level tested $\left(4.2 \mathrm{~g} \mathrm{~L}^{-1} \mathrm{dw}\right)$. An $\mathrm{EC}_{50}$ of $42.4 \pm 2.7 \mathrm{~g} \mathrm{~L}^{-1} \mathrm{dw}$ could be extrapolated.

The corresponding elutriate also had significant adverse effects on embryogenesis $(\mathrm{P}<0.0001)$. Its toxicity was not significant at concentrations $\leq 1.4 \mathrm{~g} \mathrm{~L}^{-1} \mathrm{dw}$ but increased at higher values to reach $100 \%$ of abnormalities at $14.3 \mathrm{~g} \mathrm{~L}^{-1} \mathrm{dw}$. The $\mathrm{EC}_{50}$ was $6.6 \pm 0.2 \mathrm{~g} \mathrm{~L}^{-1}$ dw.

Fig. 4 shows the linear relationships established between the concentrations of sediment extract or elutriate and the percentage of abnormalities. Covariance analysis revealed no significant difference between the two regression lines, indicating that toxicity of the sedimentary extract and elutriate was similar $(\mathrm{P}>0.05)$.

(1)

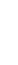




\section{Discussion}

\section{Embryotoxicity of peptaibols}

329

Long and short-sequence peptaibols were shown to disturb embryogenesis of $\underline{C \text {. gigas }}$ in the nanomolar concentration range. Toxicity of the fungal peptides was 1.3 - 8 times higher than the toxicity induced by copper for which an $\mathrm{EC}_{50}$ of $86 \pm 4 \mathrm{nM}$ was calculated. Although no significant differences between the different groups of peptaibols can be highlighted because of the important variations between replicates, toxic effects based on the estimation of $\mathrm{EC}_{50}$ appeared appreciably different. Indeed, compared to short-sequence peptaibol mixture showing an $\mathrm{EC}_{50}$ of $64 \pm 8 \mathrm{nM}$, long-sequence peptaibols were associated with a higher toxicity. $\mathrm{EC}_{50}$ of $10 \pm 3 \mathrm{nM}$ and of $31 \pm 3 \mathrm{nM}$ were, respectively, estimated for peptaibols isolated from the $\underline{T}$. longibrachiatum strain and for alamethicin mixture. Peptaibols are known to have membrane-modifying properties which are considered as the basis of their broad spectrum of bioactivity. They interact with biological membranes, modify their permeability and form voltage-dependent transmembrane ion-channels (Boheim et al., 1978; Sansom, 1993; Cafiso, 1994; Lucaciu et al., 1997; Duclohier, 2004). Leakage of cytoplasmic material can occur through such channels, leading to cell death (Chugh and Wallace, 2001). With regard to the peptides studied in our work, membrane-modifying properties were demonstrated for the long-sequence peptaibols, longibrachins, trichokonins, alamethicins, like for the short-sequence ones, trichorovins, trichorozins, harzianins HB and HK (Cafiso, 1994; Huang et al., 1994; Iida et al., 1995; Wada et al., 1995; Cosette et al., 1999; Rebuffat et al., 1999; Leclerc et al., 2001). The permeabilization process was shown to increase with the helix length and global hydrophobicity of peptaibols (Lucaciu et al., 1997; Rebuffat et al., 2000; Kropracheva and Raap, 2002; Berg et al., 2003; Grigoriev et al., 2003). Consequently, 
351

352

353

354

355

356

357

358

359

360

361

362

363

364

365

366

367

368

369

370

371

372

375

the lower embryotoxicity of short-sequence peptaibol mixture observed in our experiments could be explained by the shorter peptidic chain length.

The augmentation of peptaibol concentration in incubation media lead to a significant increase of mantle abnormalities. The different categories of abnormal larvae were defined by

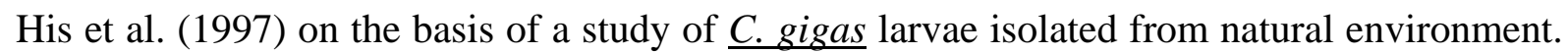
In more than 30 years of observations, all of these larvae were classified as perfectly normal straight-hinge D-larvae (His et al., 1999). D-shaped larvae with convex hinges have been described by Nice et al. (2000) as deformity related to exposure to 4-nonylphenol, an endocrine disrupter perturbing calcium metabolism. Therefore, in this investigation, protruding mantle abnormality often associated to irregular shell could be reasonably assumed to be the result of particular chemical interference of peptaibols with embryolarval development in relation to their membrane interaction properties.

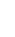

Among all their activities against different target organisms, some effects of peptaibols have been reported on animal larval models. Neurotoxicity of trichokonins was reported on blowfly larvae in millimolar concentration range (Landreau et al., 2002). The acute toxicity of fungal biocontrol agent metabolites was recently evinced using invertebrate bioassays (Artemia salina and Daphnia magna) (Favilla et al., 2006). Alamethicin was confirmed as the most toxic among the peptaibol toxins tested (alamethicin, paracelsin and antiamoebin) with LC $_{50}$ in the low micromolar range. Matha et al. (1992) reported the mosquitocidal activity of different representatives of the peptaibol group on Culex pipiens larvae in the $\mathrm{nM}-\mu \mathrm{M}$ range. These authors demonstrated that the mode of action of peptaibols was mediated through the damage to mitochondria, as a consequence of the total lysis of the internal mitochondrial contents induced by inhibition of phosphoryl transfer and uncoupling of respiration. In bivalve embryo-larval development bioassay, we could supposed that toxic effects of 


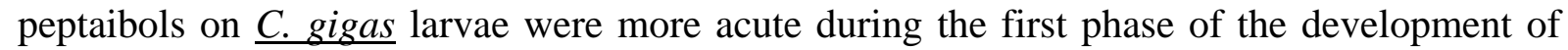
bivalve corresponding to the embryonal stages from the fertilized egg to the ciliated blastula (His et al., 1999).

Micellization studies have demonstrated that alamethicin has a limited solubility in aqueous media and aggregates above concentrations of 10-20 $\mu \mathrm{M}$ (Archer et al., 1991). A decrease of solubilized compounds in incubation media was observed during our experiment for each group of peptaibols tested and for concentrations inferior to $\mu \mathrm{M}$. This phenomenon was shown to be strongly dependent of the initial concentration. The percentage of compounds solubilized in the water column at the end of the experiment was respectively of $20 \pm 30 \%$ for the lowest concentrations tested $(<50 \mathrm{nM})$ and $70 \pm 10 \%$ for the highest ones (>200 nM). An adsorption of the amphipathic peptides on the vessels could be encountered on a limited number of fixation sites. In these conditions and since embryotoxic effects were significantly observed from the lowest concentrations ranging from 0.4 to $6 \mathrm{nM}$, the hypothesis of an early action of peptaibols during the first embryonal stages can be supported.

\section{Embryotoxicity of sediments from Ars}

A high toxicity increasing with the concentration was observed following the

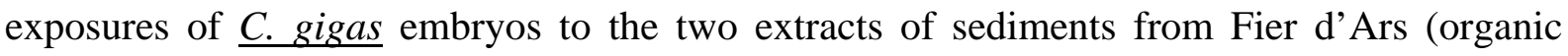
extract and elutriate).

The organic extract corresponds to an acetonic/acetic acid sedimentary extract purified on diol phase gel. Peptaibols related to longibrachins and trichokonins were detected in this extract with a concentration of $7.1 \mathrm{ng} \mathrm{g}^{-1} \mathrm{dw}$ (Poirier et al., 2007a). Consequently, an $\mathrm{EC}_{50}$ of 
$0.16 \pm 0.01 \mathrm{nM}$ of long-sequence peptaibols could be extrapolated to $\underline{C \text {. gigas }}$ embryogenesis.

402

403

404

405

406

407

408

409

410

411

412

413

414

415

416

417

418

419

420

421

422

423

424

425

Sediment elutriate corresponds to an aqueous extract of sediments containing suspended inorganic and organic particles as well as any contaminant associated with the particles or the dissolved fraction (Melzian, 1990). As is likely for many organic compounds, peptaibols may adsorb on particulate organic matter resuspended during elutriation and thus become available for $\underline{C}$. gigas embryos. The pattern of toxicity appeared to be similar between the two treatments, in spite of an estimated $\mathrm{EC}_{50}$ higher for the elutriate than that extrapolated for the organic extract. However, according to the $\mathrm{EC}_{50}$ determined for long-sequence peptaibols (10 $\pm 3 \mathrm{nM}$ ) and the environmental peptaibol concentrations, the toxic effects observed following exposure of embryos to both sedimentary treatments can not be exclusively induced by the fungal peptides.

In a previous study (Amiard-Triquet et al., 2003), the sediments from Fier d'Ars were considered as "clean" sediments since the total concentrations of metals and organic contaminants are below the first level recommended by the French regulations about sediment quality controls. We also reported a surprising high toxicity of these sediments for embryogenesis in mussel Mytilus edulis larvae, in comparable levels to those observed in the present work. Others sources of disturbance as ammonia concentrations, eutrophication or antibacterial drugs used in fish farming were examined but none can be responsible for the observed toxicity.

Although none of the biotic or abiotic stressors studied are in sufficient concentrations to explain the high toxicity of these sediments on bivalve embryogenesis, interaction involving chemical stress and other biotic factors such as peptaibols can occur in the marine environment and could be considered to explain this apparent discrepancy. Furthermore, the toxicological data obtained with pure compounds, slightly water soluble, may not represent 
426 the real extent of peptaibol embryotoxicity. The bioavailability of these molecules could be 427 augmented when they are co-solubilized with suspended particulate organic matter. 


\section{Conclusion}

The study presented herein provides the first toxicological data on peptaibol embryotoxicity on marine bivalve development. $\underline{C \text {. gigas }}$ embryos appeared to be very sensitive to fungal peptides compared to other animal larval models. It suggests that these

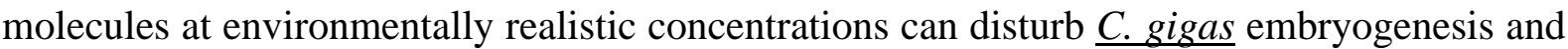
can cause an increase in larval deformities in a population of exposed animals. Further studies are necessary to evaluate whether the abnormality found in the larvae of $\underline{C \text {. gigas }}$ is disabling, or indeed lethal, and whether this deformity has arisen as a result of membrane permeability perturbations. Concentrations measured in sediments from Fier d'Ars did not fully explain the embryotoxicity observed for these sediments. Additive or synergistic toxic effects with others stressors such as phycotoxins, bacterial toxins or other chemicals usually analysed should be examined.

\section{Acknowledgement}

445 The authors thank Marion Le Goff and Xavier Caisey for their technical participation and

446 Claude Amiard-Triquet for her scientific advice. This work was partly granted by the French 447 programs MOREST coordinated by Ifremer and GERRICO (region of Pays de la Loire). 


\section{References}

452

453

454

455

456

457

458

459

460

461

462

463

464

465

466

467

468

469

470

471

472

473

474

Amiard-Triquet, C., Geffard, O., Geffard, A., Budzinski, H., Amiard, J.C., Fichet, D., Pouliquen, H., Berthelot, Y., His, E., 2003. Guideline levels of chemical contamination used to assess sediment quality in coastal areas: a contribution to understanding false negative or false positive responses. In: Tremblay, H., Locat, J., Galvez-Cloutier, R. (Eds.), Contaminated Sediments : Characterization, Evaluation, Mitigation/Restoration. Univ. Laval, Québec, pp. 349-354.

Archer, S.J., Ellena, J.F., Cafiso, D.S., 1991. Dynamics and aggregation of the peptide ion channel alamethicin. Measurements using spin-labeled peptides. Biophys. J. 60, 389398.

Augeven-Bour, I., Rebuffat, S., Auvin, C., Goulard, C., Prigent, Y., Bodo, B., 1997. Harzianin HB I, an 11-residue peptaibol from Trichoderma harzianum: isolation, sequence, solution synthesis and membrane activity. J. Chem. Soc., Perkin trans., I 10, 1587-1594.

Becker, D., Kiess, M., Brückner, H., 1997. Structures of peptaibols antibiotics hypomurocin A and B from the ascomycetous fungus Hypocrea muroiana Hino et Katsumoto. Lieb. Ann. Recueil., 767-772.

Berg, A., Grigoriev, P.A., Degenkolb, T., Neuhof, T., Härtl, A., Schlegel, B., Gräfe, U., 2003. Isolation, structure elucidation and biological activities of trichofumins A, B, C and D, new 11 and 13mer peptaibols from Trichoderma sp. HKI 0276. J. Pept. Sci. 9, 810816.

Boheim, G., Irmscher, G., Jung, G., 1978. Trichotoxin A-40, a new membrane-exciting peptide. Part B. Voltage-dependent pore formation in bilayer lipid membranes and 
comparison with other alamethicin analogues. Biochim. Biophys. Acta-Biomembr. 507, 485-506.

Cafiso, D., 1994. Alamethicin: a peptide model for voltage gating and protein-membrane interactions. Annu. Rev. Biophys. Biomolec. Struct. 23, 141-165.

Chugh, J.K., Wallace, B.A., 2001. Peptaibols: Models for ion channels. Biochem. Soc. Trans. 29, 565-570.

Connor, P.M., 1972. Acute toxicity of heavy metals to some marine larvae. Mar. Pollut. Bull. 3, 190-192.

Cosette, P., Rebuffat, S., Bodo, B., Molle, G., 1999. The ion-channel activity of longibrachins LGA I and LGB II: effects of Pro-2/Ala and Gln-18/Glu substitutions on the alamethicin voltage-gated membrane channels. Biochim. Biophys. Acta-Biomembr. $1461,113-122$.

Degenkolb, T., Berg, A., Gams, W., Schlegel, B., Gräfe, U., 2003. The occurence of peptaibols and structurally related peptaibiotics in fungi and their mass spectrometric identification via diagnostic fragment ions. J. Pept. Sci. 9, 666-678.

Degenkolb, T., Gräfenham, T., Berg, A., Nirenberg, H., Gams, W., Brückner, H., 2006. Peptaibiomics: Screening for polypeptide antibiotics (peptaibiotics) from plantprotective Trichoderma species. Chem. Biodivers. 3, 593-610.

Duclohier, H., 2004. Helical kink and channel behaviour: A comparative study with the peptaibols alamethicin, trichotoxin and antiamoebin. Eur. Biophys. J. 33, 169-174.

Emmens, C.W., 1948. Principles of biological assays. Chapman and Hall, London.

Favilla, M., Macchia, L., Gallo, A., Altomare, C., 2006. Toxicity assessment of metabolites of fungal biocontrol agents using two different (Artemia salina and Daphnia magna) invertebrate bioassays. Food Chem. Toxicol. 44, 1922-1931. 
Geffard, O., His, E., Budzinski, H., Chiffoleau, J.F., Coynel, A., Etcheber, H., 2004. Effects of storage method and duration on the toxicity of marine sediments to embryos of Crassostrea gigas oysters. Environ. Pollut. 129, 457-465.

Grigoriev, P.A., Schlegel, B., Kronen, M., Berg, A., Härtl, A., Gräfe, U., 2003. Differences in membrane pore formation by peptaibols. J. Pept. Sci. 9, 763-768.

His, E., Seaman, M.N.L., Beiras, R., 1997. A simplification the bivalve embryogenesis and larval development bioassay method for water quality assessment. Wat. Res. 31, 351355.

His, E., Beira, R., Seaman, M.N.L., 1999. The assessment of marine pollution: bioassays with bivalve embryos and larvae. Adv. Mar. Biol. 37, 1-178.

Huang, Q., Tezuka, Y., Kikuchi, T., Momose, Y., 1994. Trichokonin VI, a new $\mathrm{Ca}^{2+}$ channel agonist in bullfrog cardiac myocytes. Eur. J. Pharmacol. 271, R5-R6.

Huang, Q., Tezuka, Y., Hatanaka, Y., Kikuchi, T., Nishi, A., Tubaki, K., 1995. Studies on metabolites of mycoparasitic fungi. IV. Minor peptaibols of Trichoderma koningii. Chem. Pharm. Bull. 43, 1663-1667.

Huang, Q., Tezuka, Y., Hatanaka, Y., Kikuchi, T., Nishi, A., Tubaki, K., 1996. Studies on metabolites of mycoparasitic fungi. V. Ion-spray ionization mass spectrometric analysis of trichokonin-II, a peptaibol mixture obtained from the culture broth of Trichoderma koningii. Chem. Pharm. Bull. 44, 590-593.

Iida, A., Sanekata, M., Wada, S.I., Fujita, T., Tanaka, H., Enoky, A., Fuse, G., Kanai, M., Asami, K., 1995. Fungal metabolites. XVIII. New membrane-modifying peptides, Trichorozins I-IV, from the fungus Trichoderma harzianum. Chem. Pharm. Bull. 43, 392-397.

Kirschbaum, J., Krause, C., Winzheimer, R.K., Brückner, H., 2003. Sequences of alamethicins F30 and F50 reconsidered and reconciled. J. Pept. Sci. 9, 799-809. 
524 Krause, C., Kirschbaum, J., Brückner, H., 2006. Peptaibiomics: An advanced, rapid and selective analysis of peptaibiotics/peptaibols by SPE/LC-ES-MS. Amino Acids 30, 435-443.

Kropracheva, T., Raap, J., 2002. Ion transport across a phospholipid membrane mediated by the peptide trichogin GA IV. Biochim. Biophys. Acta 1567, 193-203.

Landreau, A., Pouchus, Y.F., Biard, J.F., Sallenave-Namont, C., Robiou du Pont, T., Verbist, J.F., 2002. Combined use of LC/MS and biological test during rapid identification of marine mycotoxins produced by Trichoderma koningii. J. Microbiol. Meth. 48, 181194.

Leclerc, G., Rebuffat, S., Goulard, C., Bodo, B., 1998. Directed biosynthesis of peptaibol antibiotics in two Trichoderma strains. I. Fermentation and isolation. J. Antibiot. 51, 170-177.

Leclerc, G., Goulard, C., Prigent, Y., Bodo, B., Wroblewski, H., Rebuffat, S., 2001. Sequences and antimycoplamic properties of longibrachins LGB II and LGB III, two novel 20-resiude peptaibols from Trichoderma longibrachiatum. J. Nat. Prod. 64, 164170.

Lucaciu, M., Rebuffat, S., Goulard, C., Duclohier, H., Molle, G., Bodo, B., 1997. Interaction of the 14-residue peptaibols, harzianins HC, with lipid bilayers: permeability modifications and conductance properties. Biochim. Biophys. Acta 1323, 85-96.

Martin, M., Osborn, K.E., Billig, P., Glickstein, N., 1981. Toxicities of ten metals to Crassostrea gigas and Mytilus edulis embryos and Cancer magister larvae. Mar. Pollut. Bull. 12, 305-308.

Matha, V., Jegorov, A., Kiess, M., Brückner, H., 1992. Morphological alterations accompanying the effect of peptaibiotics, alpha-aminoisobutyric acid-rich secondary metabolites of filamentous fungi, on Culex pipiens larvae. Tissue Cell 24, 559-564. 
Melzian, B.D., 1990. Toxicity assessment of dredged materials: acute and chronic toxicity as determined by bioassays and bioaccumulation tests. In: Alzieu, C., Gallenne, B. (Eds.), Proceedings of the International Seminar on Environmental Aspects of Dredging Activities. Port autonome de Nantes Saint-Nazaire, Nantes, France, pp. 4964.

Mohamed-Benkada, M., Montagu, M., Biard, J.F., Mondeguer, F., Vérité, P., Dalgalarrondo, M., Bissett, J., Pouchus, Y.F., 2006. New short peptaibols from a marine Trichoderma strain. Rapid Commun. Mass Spectrom. 20, 1176-1180.

Nice, H.E., Thorndyke, M.C., Morritt, D., Steele, S., Crane, M., 2000. Development of Crassostrea gigas Larvae is Affected by 4-nonylphenol. Mar. Pollut. Bull. 40, 491496.

Peltola, J., Ritieni, A., Mikkola, R., Grigoriev, P.A., Pocsfalvi, G., Andersson, M.A., Salkinoja-Salonen, M.S., 2004. Biological effects of Trichoderma harzianum peptaibols on mammalian cells. Appl. Environ. Microbiol. 70, 4996-5004.

Poirier, L., Amiard, J.C., Mondeguer, F., Quiniou, F., Ruiz, N., Pouchus, Y.F., Montagu, M., 2007a. Determination of peptaibol trace amounts in marine sediments by liquid chromatography / electrospray ionization - ion trap - mass spectrometry. J. Chromatogr. A in press.

Poirier, L., Montagu, M., Landreau, A., Mohammed-Benkada, M., Grovel, O., SallenaveNamont, C., Biard, J., Amiard-Triquet, C., Amiard, J.C., Pouchus, Y.F., 2007b. Peptaibols, stable markers of fungal development in the marine environment. Chem. Biodivers. in press.

Quiniou, F., His, E., Delesmont, R., Caisey, X., 2005. Bio-indicateur de la toxicité potentielle de milieux aqueux: bio-essai "développement embryo-larvaire de bivalve". In: Ifremer (Ed.), Méthodes d'analyse en milieu marin, pp. 24. 
574 Rebuffat, S., Hlimi, S., Prigent, Y., Goulard, C., Bodo, B., 1996. Isolation and structural elucidation of the 11-residue peptaibol antibiotic, harzianin HK VI. J. Chem. Soc., Perkin trans., I 16, 2021-2027.

Rebuffat, S., Goulard, C., Bodo, B., Roquebert, M.F., 1999. The peptaibol antibiotics from Trichoderma soil fungi; structural diversity and membrane properties. Recent Res. Devel. Org. Bioorg. Chem. 3, 65-91.

Rebuffat, S., Goulard, C., Hlimi, S., Bodo, B., 2000. Two unprecedented natural Aib-peptides with the (Xaa-Yaa-Aib-Pro) motif and an unusual C-terminus: Structures, membranemodifying and antibacterial properties of pseudokonins KL III and KL VI from the fungus Trichoderma pseudokoningii. J. Pept. Sci. 6, 519-533.

Sallenave-Namont, C., Pouchus, Y.F., Bardouil, M., Lassus, P., Roquebert, M.F., Verbist, J.F., 1999. Bioaccumulation of mycotoxins by shellfish: Contamination of mussels by metabolites of a Trichoderma koningii strain isolated in the marine environment. Toxicon 37, 77-83.

Sansom, M., 1993. Structure and function of channel-forming peptaibols. Q. Rev. Biophys. 26, 365-421.

Szekeres, A., Leitgeb, B., Kredics, L., Antal, Z., Hatvani, L., Manczinger, L., Vagvölgyi, C., 2005. Peptaibols and related peptaibiotics of Trichoderma: A review. Acta Microbiol. Immunol. 52, 137-168.

Vindimian, E., Robaut, C., Fillion, G., 1983. A method for cooperative and non cooperative binding studies using non linear regression analysis on a microcomputer. J. App. Biochem. 5, 261-268.

Wada, S.I., Iida, A., Akimoto, N., Kanai, M., Toyama, N., Fujita, T., 1995. Fungal metabolites. XIX. Structural elucidation of channel-forming peptides, Trichorovins - IXIV, from the fungus Trichoderma viridae. Chem. Pharm. Bull. 43, 910-915. 
599 Whitmore, L., Wallace, B.A., 2004a. Analysis of peptaibol sequence composition: 600 Implications for in vivo synthesis and channel formation. Eur. Biophys. J. 33, 233-237. 601 Whitmore, L., Wallace, B.A., 2004b. The Peptaibol Database: A database for sequences and 602 structures of naturally occurring peptaibols. Nucleic Acids Res. 32, 593-594.

603 Xiao-Yan, S., Qing-Tao, S., Shu-Tao, X., Xiu-Lan, C., Cai-Yun, S., Yu-Zhong, Z., 2006. 604 Broad-spectrum antimicrobial activity and high stability of Trichokonins from 605 Trichoderma koningii SMF2 against plant pathogens. FEMS Microbiol. Lett. 260, 606 119-125.

607

608 
610

611 Figure 1 : MS spectra of the two main peptaibol fractions isolated from $\underline{T \text {. longibrachiatum }}$ marine strain. A : $[\mathrm{M}+\mathrm{Na}]^{+}$ions of short-sequence peptaibol mixture (respectively: $t_{R}=8.2$, 9.5, 11.2 and $12 \mathrm{~min})$; B-D: doubly charged $[\mathrm{M}+2 \mathrm{Na}]^{2+}$ ions of long-sequence peptaibol

614 mixture observed at respectively $t_{R}$ of 5.1, 8.8 and 9.8 min.

615

616

Figure 2 : Normally developed D-shaped larva (A) and D-shaped larva with a protruding mantle associated to an irregular shell margin (B). Scale bars: $10 \mu \mathrm{m}$.

619

620

621 Figure 3 : Peptaibol concentration effects on percentages of abnormal Crassostrea gigas development $( \pm$ SD). Alamethicin $(-\bullet-)$, long-sequence peptaibol mixture (---ø---), shortsequence peptaibol mixture $(\cdots \cdot \mathbf{\Delta} \cdots \cdot)$.

624

625

Figure 4 : Effect of the sediment treatments on percentages of abnormal Crassostrea gigas development $( \pm \mathrm{SD})$ : organic extract $(--\circ--)(r=0.97, \mathrm{n}=4)$, elutriate $(-\bullet-)(r=0.98, n=$ 628 $5)$.

629

630

631

632

633

634

635 
636

Figure 1

637

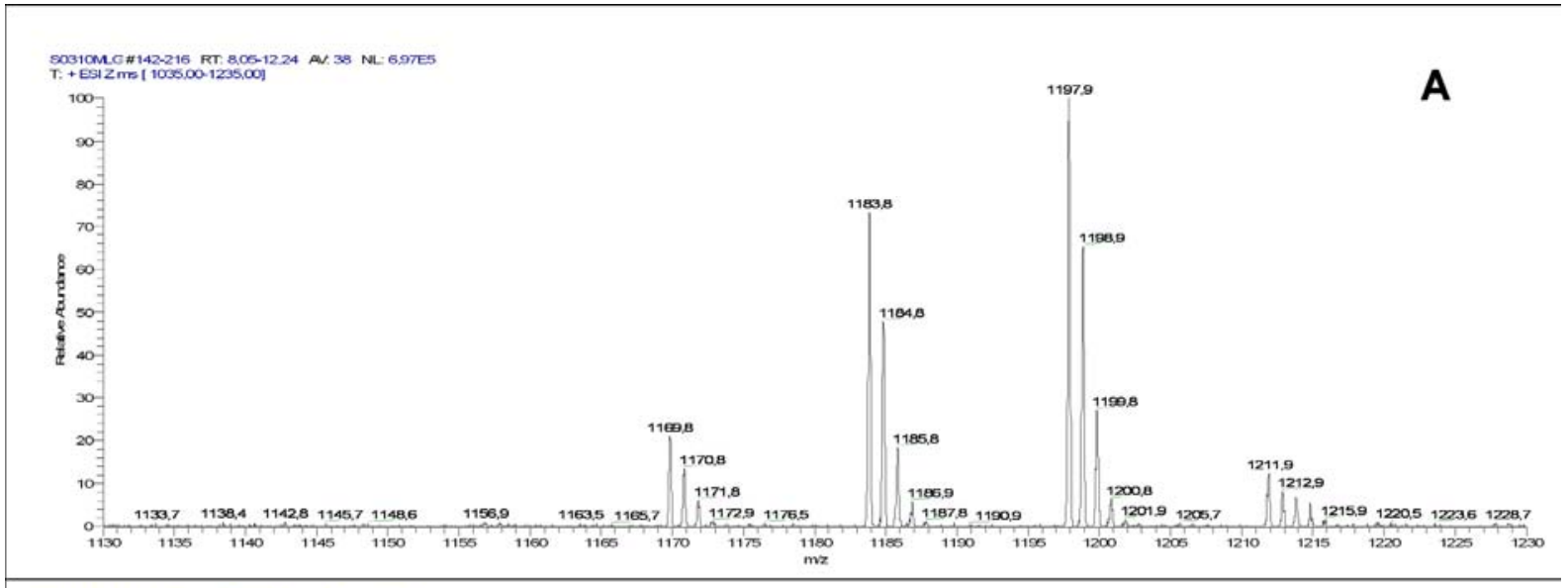

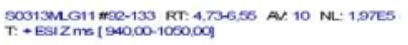

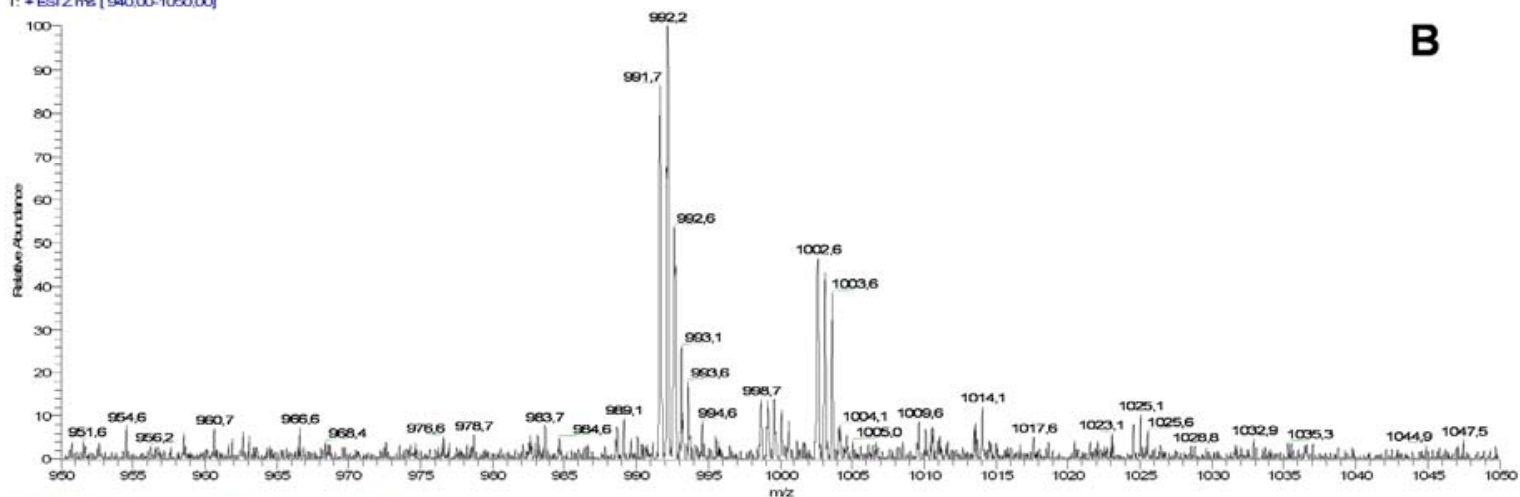

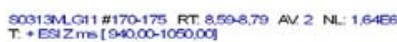

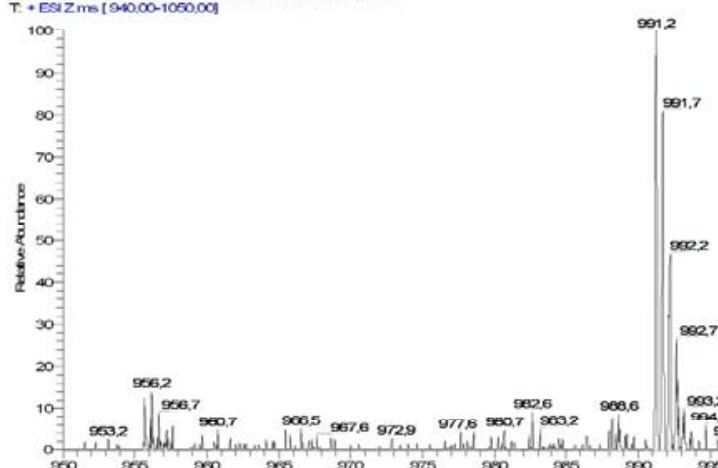

C

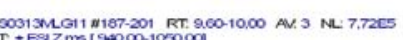

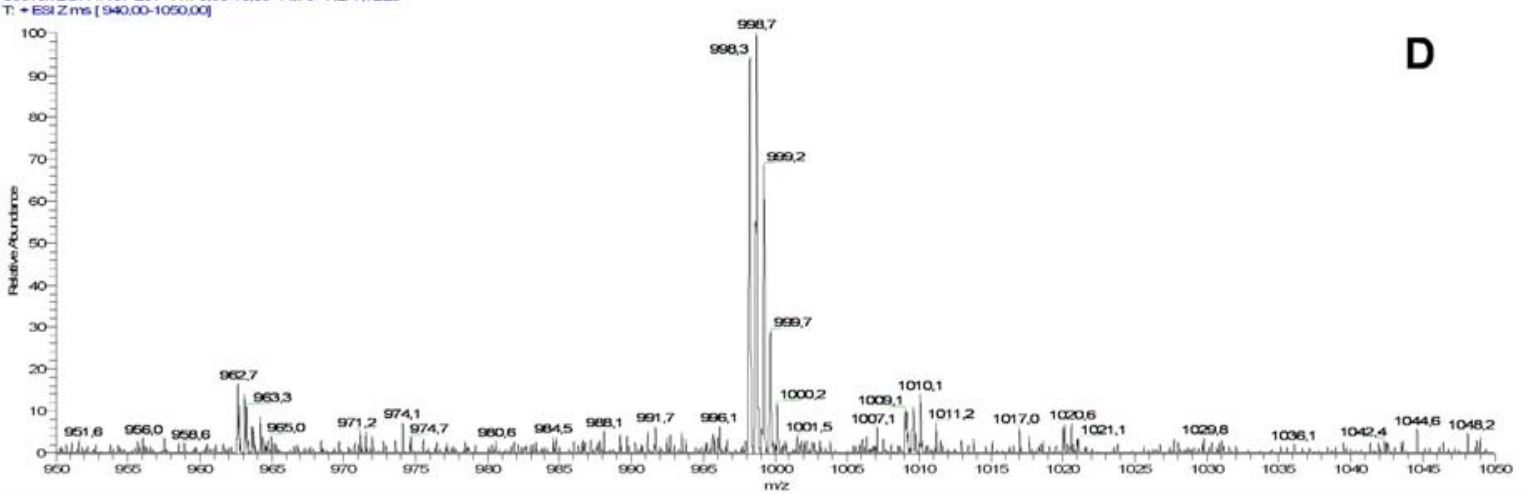


641 Figure 2

642
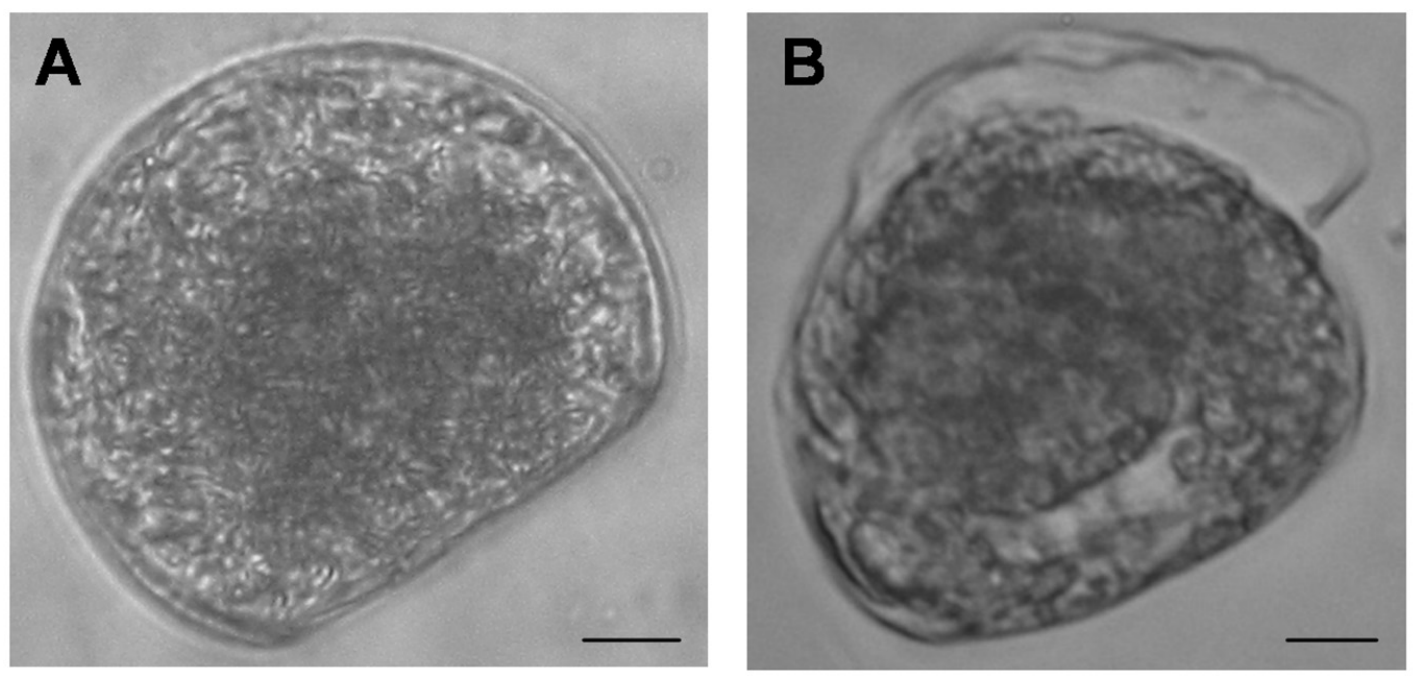

643

644

645

646

647

648

649

650

651

652

653

654

655

656

657

658

659

660

661

662

663 
664 Figure 3

665

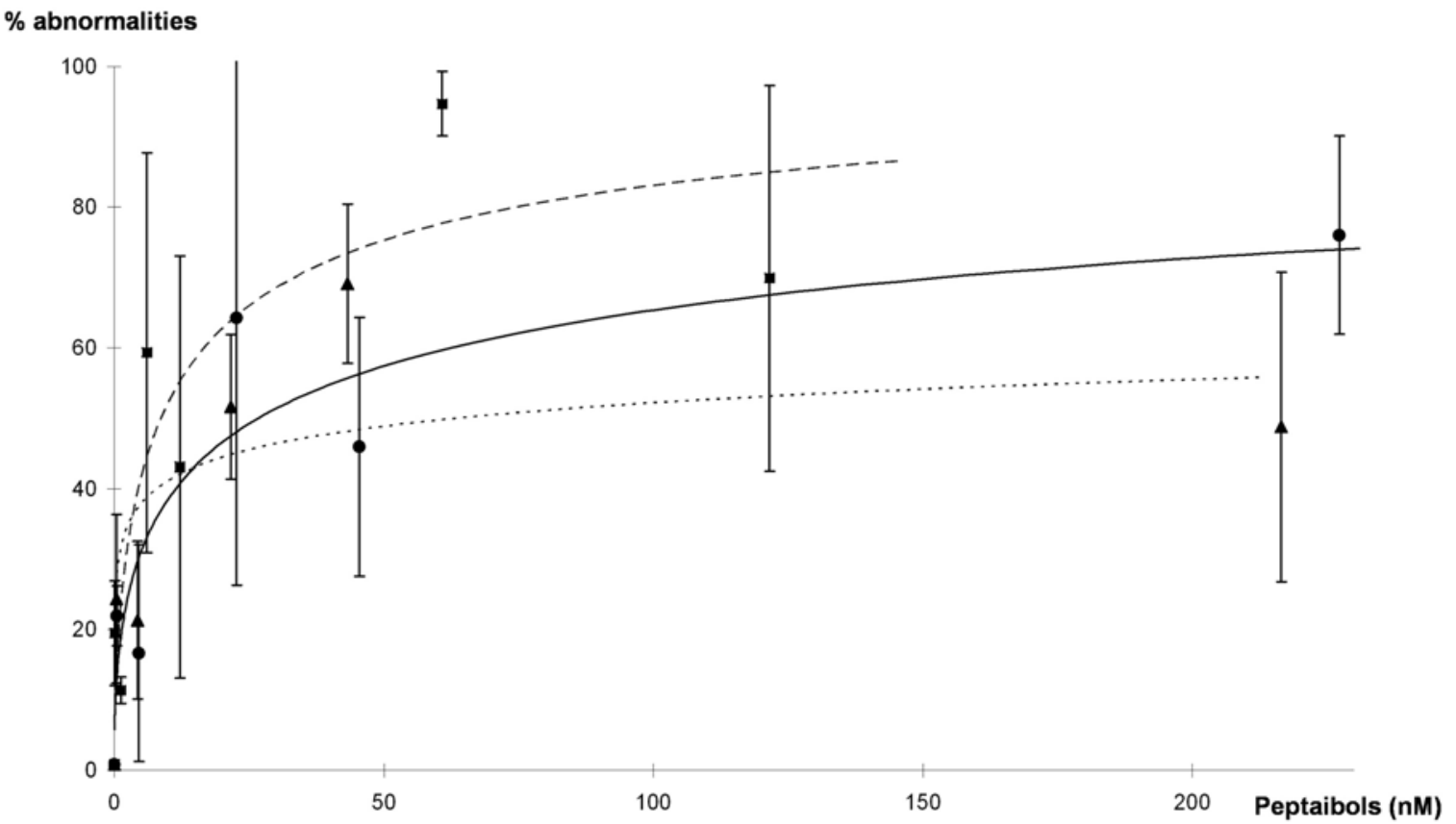

666

667

668

669

670

671

672

673

674

675

676

677

678

679

680

681 
32

682

683

Figure 4

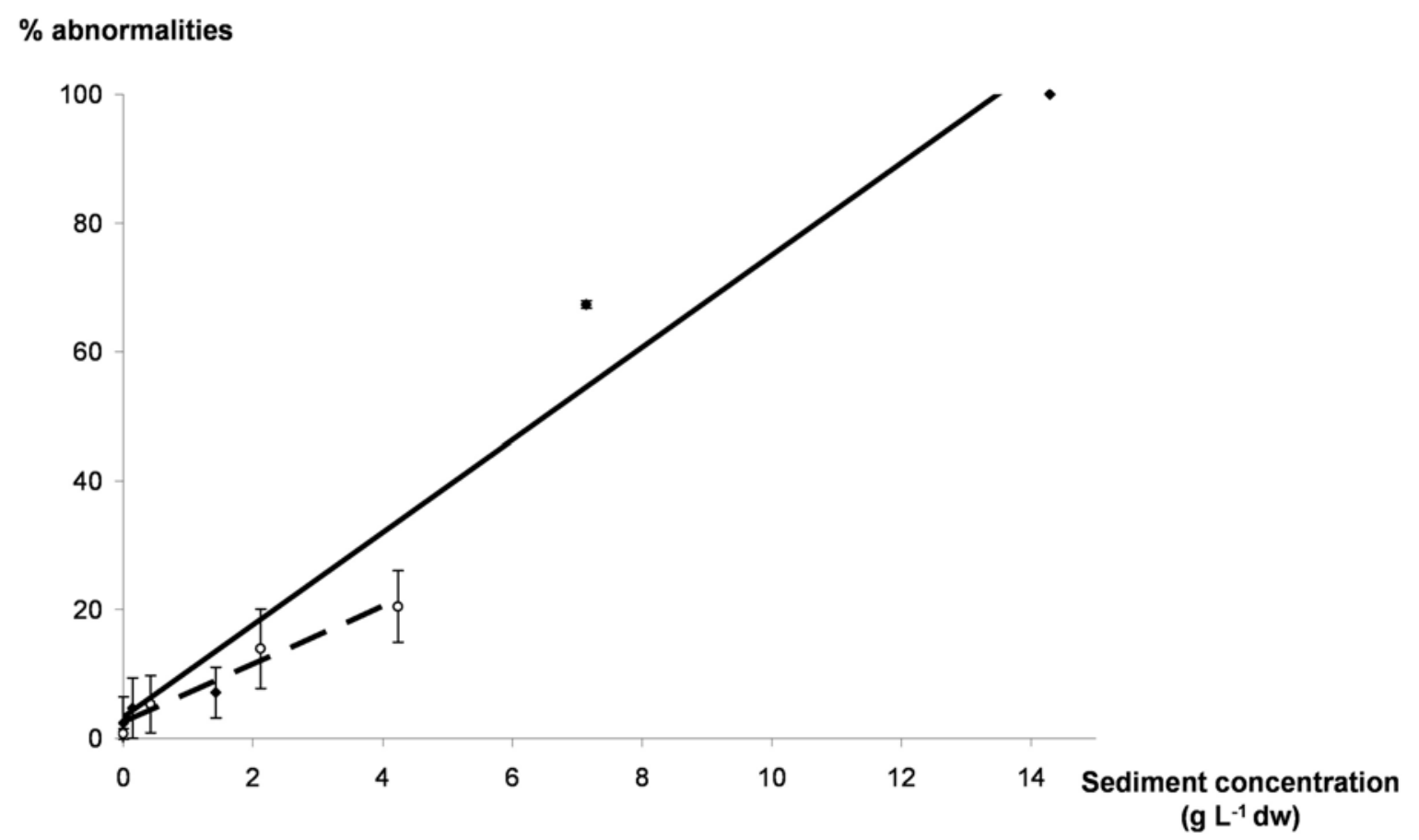

684 